\title{
Development of patient satisfaction questionnaires: II. Collaboration in practice
}

\author{
Martin Eccles, Ann Jacoby, Claire Bamford
}

The degree to which patients are satisfied (or dissatisfied) with their medical care has increasingly come to be seen as an essential component in the evaluation of services. ${ }^{1} \mathrm{~A}$ common way of undertaking patient satisfaction surveys has been to commission an external agency to undertake a survey of "the patient in the street". Although such surveys can provide valuable information to administrative bodies, they have two major drawbacks which limit their usefulness to individual general practices. Firstly, their content is usually specified by non-practitioner administrators or researchers, or both. Individual practices therefore, do not have an opportunity to use the surveys to explore issues of particular concern to them. Secondly, these surveys are usually administered to a random sample of patients registered with all practices within an administrative area and the results are presented in aggregated form. Since practices are not provided with individualised feedback about the views of their own patients they cannot identify what changes, if any, are needed. Conversely, it is easy for individual practices to avoid difficult or problematic results. The presentation of results as aggregated values also removes the potential for comparison between practices.

In the accompanying paper $(p \text { 000) })^{2}$ Bamford and Jacoby described the development of a questionnaire survey to assess patient satisfaction with access to services and interpersonal aspects of care in five local general practices using an alternative approach designed to avoid these drawbacks. We describe the experience of the group of general practitioners and practice managers who were involved in this work.

\section{Evolution of the group}

In September 1990 Newcastle upon Tyne Medical Audit Advisory Group (MAAG), which had been constituted as one of four "pilot" MAAGs, ${ }^{3}$ held its first open day, which included small group work centered around problems appropriate for audit.

One group considered the question: "How would you know whether you as a practice are giving enough appointments and by what standards would you judge?" This raised the issue of patient satisfaction. At the suggestion of the group leader this group met again after the open day to consider using postal questionnaires to assess patient satisfaction in their practices. Recognising that they did not have the necessary skills in research and questionnaire design, the group co-opted a general practitioner with research experience (ME) and two social researchers (AJ, CB) from the centre for health services research at this university. The group also co-opted the MAAG coordinator and the MAAG audit assistant whom it envisaged would be involved with the continued administering of the questionnaires after they had been developed. The two social researchers required funding, which was negotiated between the MAAG chairman and the general manager of the family health services authority (FHSA).

Co-opting these five people almost doubled the size of the original group of four general practitioners and two practice managers. However, the group remained cohesive and task oriented, and meetings were lively and enjoyable. The task had become to develop two postal questionnaires to measure patient satisfaction with access to care and with interpersonal aspects of care.

As the group members were not representatives of their practices but interested individuals it was considered important that their practices be fully informed of the project's progress. The practices obviously had to agree that patients could be sent postal questionnaires, and this did not present a problem. The issue of who saw the results exercised the group, the practices, and the MAAG somewhat more. Although the group members themselves were not threatened by the prospect of sharing potentially critical results, they were aware that they had no remit to discuss any results before those results had been seen by the respective practices. Therefore results specific to practices were not disclosed within the group unless and until this had been agreed by the practices.

The group's relationship with the FHSA was also an issue. As the funding body the FHSA required a report at the end of the work; there were differing opinions among the practices about disclosing practice specific results to the FHSA. In the event, the FHSA made it clear that it was not interested in identifiable practice data, wanting only aggregated results.

\section{Feedback}

The issue of feedback was discussed at a theoretical level, and the social researchers suggested several alternative ways in which the results could be presented. The group opted for a combination of tables and bar charts with superimposed scores. These provided a comparison of an individual practice with the average of the other four practices in the 
group. Since providing averages masked the variation between individual practices maximum and minimum values were also included in each figure or table. Table 1 and figure 1 are examples of the feedback from the questionnaire on access and table 2 and figure

Table 1 Percentages of patients who saw the doctor of their choice, by practice and sex of doctor

\begin{tabular}{lcc}
\hline & Female doctor & Male doctor \\
\hline Your practice & $76 \%$ & $95 \%$ \\
The other practices & $91 \%$ & $90 \%$ \\
Range & $76-100 \%$ & $86-95 \%$ \\
\hline Total (No) & $85 \%(123)$ & $92 \%(266)$ \\
\hline
\end{tabular}

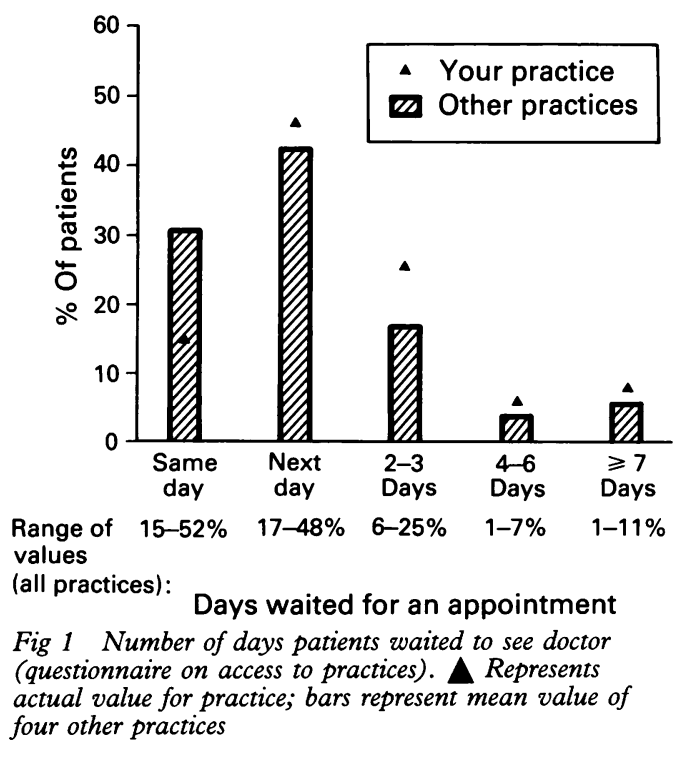

Table 2 Patients' reasons for not raising queries during consultation, by practice

\begin{tabular}{lccrc}
\hline & $\begin{array}{c}\text { Your practice } \\
(\%)\end{array}$ & $\begin{array}{c}\text { Other practices } \\
(\%)\end{array}$ & $\begin{array}{c}\text { Range } \\
(\%)\end{array}$ & $\begin{array}{c}\text { Total } \\
(\%)\end{array}$ \\
\hline Did not occur to do so at the time & 31 & 35 & $29-46$ & 34 \\
Did not want to bother the doctor & 25 & 35 & $25-39$ & 33 \\
Felt rushed by the doctor & 36 & 20 & $7-36$ & 23 \\
Worried about other waiting patients & 6 & 5 & $0-13$ & 5 \\
Other reason & 3 & 5 & $2-10$ & 5 \\
\hline Total No & 36 & 131 & & 167 \\
\hline
\end{tabular}

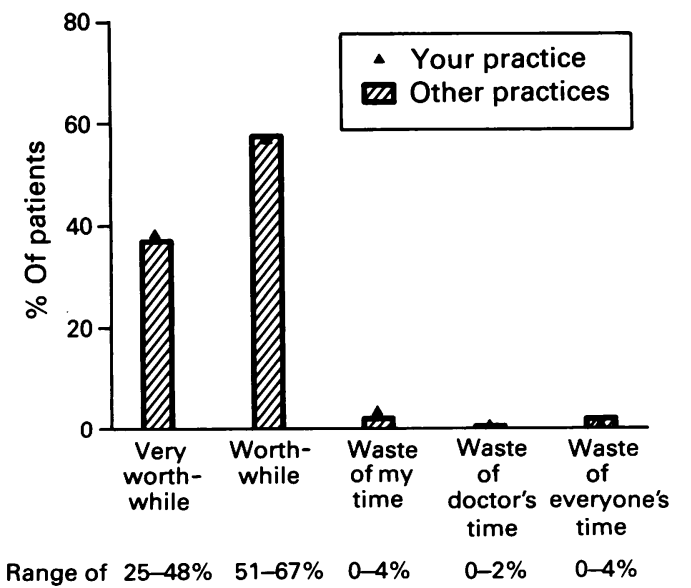

values

(all practices):

Overall views of consultation

Fig 2 Patients' overall views of the value of consultation (questionnaire on interpersonal aspects of care). Represents actual value for practice; bars represent mean value of four other practices
2 of that from the questionnaire on interpersonal aspects of care. By providing a comparison of one practice against the mean of the four others and quoting the range for the values of all five practices, an individual practice could get a clear idea of how it compared with other practices. Such a format would not, however, explain the reasons for any differences.

Changes made in response to feedback

In response to the feedback four of the practices introduced changes. These included changes in the guidelines given to receptionists on talking to patients by telephone and in person; in surgery times, to make it easier for parents to attend with children on the way home from school; in the booking arrangements for surgeries, to ensure that slots were left for same day appointments; in providing information about surgery times; and in the pattern of surgery booking, to try to avoid consultations running late. Also one practice manager now sets aside up to half an hour a day to talk to patients in the waiting room to canvass their views on the practice more informally. Additionally, the results showed that one practice had a shortage of female doctor time and this will be a consideration in a forthcoming change of partnership.

One practice said that the questionnaire did not disclose anything that was not already known to it. However, until the results were presented to that practice it had never effectively addressed the issue that arose. As a direct result of involvement in this work one practice, which is a fundholding practice, now feels more comfortable dealing with the issue of patient satisfaction and is currently working with the Community Health Council in this area.

All of the changes related to issues of accessibility. Although questions about the interpersonal aspects of care were included, the results did not produce any changes despite showing marked variation in satisfaction between practices. This may have been because the information collected was specific to the practice rather than to the doctors or because doctors found it less threatening to accept criticisms of accessibility than of their interpersonal skills.

One practice chose not to implement any changes. This may have been because its representative was a co-opted member of the group whereas the original group members had become involved because of explicit concerns about the topic.

\section{Benefits and costs}

Although a precise analysis is not possible, some of the benefits and costs of the work are clearly identifiable. Perhaps the most important benefit was the ability of the exercise to stimulate change within practices. Four of the practices introduced changes in response to their feedback and have expressed interest in repeating the survey in two years' time to examine the impact of these changes. 
The work has produced two validated questionnaires available to Newcastle MAAG and other Newcastle practices as an "off the shelf" tool. Several practices in Newcastle and five other MAAGs have expressed interest in conducting similar surveys that draw on the experience of the group. The results from this group of five practices can be used to set up a database against which other practices using the questionnaires can compare their results. Finally, an important benefit was that the group found the experience enjoyable and rewarding.

The financial cost of the survey to the FHSA was $£ 16000$, most of which was for the salaries of the two social researchers; the remainder covered printing and postage costs and some clerical work. The other major cost was the time spent by group members - 15 evening meetings of one and a half hours over the course of a year; however these were accredited for postgraduate education allowance.
We think that the benefits clearly outweighed the costs and would recommend such a collaborative approach to MAAGs, FHSAs, and other interested groups, not only within patient satisfaction but also in other areas of primary care audit.

We thank Dr Tim van Zwanenberg, who initiated the project, Newcastle upon Tyne MAAG for its support; Dr Allen Hutchinson, programme director, Centre for Health Services Research; Mr Terry Marshall, general manager, Newcastle upon Tyne FHSA; and Newcastle upon Tyne FHSA for funding the project. This paper is written on behalf of the group, Alison Richardson, Maureen Rillands, and Louise Young.

1 Hopkins A, Costain D, eds. Measuring the outcomes of medical care. London: Royal College of Physicians and Kedical care. London: Royal

2 Bamford C, Jacoby A. Development of patient satisfaction questionnaires: I. Methodological issues. Quality in questionnaires: I. Method

3 Newcastle upon Tyne Family Health Services Authority Medical Audit Advisory Group. Learning by doing. (Chairman's report on a pilot study.) Newcastle upon Tyne: Newcastle upon Tyne FHSA, 1990. 